\title{
Toward Creating a New Research Tool: Operationally Defining Cyberterrorism
}

\author{
Gregg R. Murray*, Craig Douglas Albert, Kim Davies, Candace Griffith, \\ John J. Heslen, Lance Y. Hunter, Nadia Jilani-Hyler, and Sudha Ratan
}

Augusta University

March 23, 2019

\begin{abstract}
The purpose of this essay is to present a theoretically informed and operationally useful definition of cyberterrorism to advance research in the fields of terrorism and cyberscience as well as to inform policy makers. The operationalization distinguishes terrorist events that are distinctly and fundamentally cyber in nature from those that are not. It frames cyberterrorism as a form of aggression and distinguishes it from other forms of cyber aggression: cyberwar, cyber espionage, cybercrime, and cyber mischief. The essay includes illustrative cases to identify key features of cyberterrorist events relative to other cyber and non-cyber aggression and concludes with a clear process to classify cyber aggression as cyberterrorism or not.
\end{abstract}

KEYWORDS: cyberterrorism, terrorism, cyber war, cyberspace, aggression

* Corresponding author: gmurray@augusta.edu 
Individuals, groups, and nations have been trying to exert political, social, and economic control over others for millennia. Often these attempts have leveraged transformative technologies to pursue power, from bronze weapons wielded by Hyksosian conquerors against Egyptian soldiers around 1700 BCE and gunpowder-charged weapons deployed by Chinese defenders against invading Mongols in 1232 CE to nuclear weapons unleashed by American bombers against the Japanese mainland in 1945 . With the profound changes that have occurred via the advent of the digitally networked world and mass information storage (Rosenzweig 2013), it is now clear that cybertechnology is positioned to take its place among these disruptive forces in the pursuit of the control of others (Borghard and Lonergan 2017). Physically destructive cyber attacks against an Australian waste management system in 2001 (Sayfayn and Madnick 2017), Iranian uranium enrichment facility in 2010 (Langner 2013), and a German steel maker's mill control system in 2014 (BBC News 2014) serve as early demonstrations of the potency of an evolving and expansive cybertechnology threat.

But the defining characteristics of cybertechnology's role are still in question. As Sanger noted, "After a decade of hearings in Congress, there is still little agreement on whether and when cyberstrikes constitute an act of war, an act of terrorism, mere espionage, or cyberenabled vandalism" $(2018, x v)$. This essay describes and defines the emerging role of "cyber" in terrorism in an effort to present a theoretically informed and operationally useful definition of cyberterrorism. The definition will distinguish terrorist events that are characterized as cyber in nature from those that are not. It will also distinguish cyberterrorist events from other forms of cyber aggression. We propose that a fundamental conceptualization of cyberterrorism such as 
this will help advance both terrorism and cyberscience research as well as help inform the policy makers responsible for responding to cyberterrorism.

In this endeavor, this essay next presents a definition of "cyber" and a typology of cyber aggression that provides a theoretical framework for distinguishing cyberterrorism from other forms of cyber aggression. Then it offers a definition of cyberterrorism along with pertinent cases that clarify important dimensions and distinctions. With the foundational concepts laid, it continues with definitions of cyber mischief, cybercrime, cyber espionage, and cyberwar along with cases that further help distinguish each from cyberterrorism and clarifies our definition of cyberterrorism. Finally, the essay concludes by integrating the concepts into a broad overview intended to provide researchers with a clear, step-by-step process to identify and then classify cyber aggressions as cyberterrorism or not.

\section{SOME DEFINITIONS OF CYBER}

There is no single, widely accepted definition of the term "cyber." Popular definitions, such as that offered by the Oxford Dictionary, tend to focus on concepts related to computers, information technology, and virtual reality, while expert definitions capture more nuanced characteristics. For example, security scholars Valeriano and Maness simply define it as "computer or digital interactions" $(2015,22)$. Finland's directive on cyber security strategy states that the term cyber "usually relates to electronic information (data) processing, information technology, electronic communications (data transfer) or information and computer systems" (Secretariat of the Security and Defence Committee [Finland] 2013, 12).

Often, these activities use technological devices unrestricted by physical and geographical 
borders (Maras 2017). They occur in "an operational domain framed by the use of electronics and the electromagnetic spectrum to create, store, modify, exchange, and exploit information via interconnected and internetted information systems and their associated structures" often referred to as "cyberspace" (Kuehl 2009, 28). As generally construed, cyberspace encompasses "all computer, network, digital, cellular, fiber, and space-based forms of communications, interactions, and interconnections" (Valeriano and Maness 2015, 22). Cyber operations, as defined by the U.S. Joint Chiefs of Staff, are conducted through any "device, computer program, or technique, including any combination of software, firmware, or hardware" (Joint Staff Director of Operations 2013, I-6). Aggregating these conceptions into a workable definition, we define cyber activities as computer-mediated acts conducted via electronic networks (Thomas and Loader 2000).

\section{A TYPOLOGY OF CYBER AGGRESSION}

One way to understand the use of cyber activities as a means to control others is to think of cyber activities as a potential form of aggression. Broadly speaking, researchers define aggression as an act that is intentionally carried out to cause harm to another actor who is motivated to avoid that harm (e.g., DeWall, Anderson, and Bushman 2011). The harm experienced by a target of aggression can be physical, psychological, or relational. While there are many ways to categorize the acts of aggressors, one widely used approach distinguishes between physical aggression, verbal aggression, anger indicating an emotional state, and hostility indicating a cognitive state (Buss and Perry, 1992). Physical aggression includes behavior such as physically striking or threatening another, while verbal aggression includes 
being disagreeable or argumentative with another. On the other hand, anger includes emotional flare-ups or temperamental outbursts, while hostility includes feelings of bitterness or haplessness (Bryant and Smith 2001).

With our conceptions of cyber activities and aggression in mind, we define cyber aggression as a computer-mediated act consequentially conducted through electronic networks to intentionally harm another actor that is motivated to avoid the harm. This means the act must be conducted using hardware, software, or firmware (JCS 2013, I-6) to exploit a computerized, networked, digital, cellular, fiber, or space-based interaction or interconnection (Valeriano and Maness 2015). Because aggression also occurs in the real world and to distinguish real-world from cyber aggression, the definition indicates that cyber must play a consequential or essential role in the act such that the act exists only or primarily because of its cyber nature or that the conduct of the act requires expertise in cybertechnology beyond that of the typical user of cybertechnology. It also requires that the act be intentional and manifested by physical aggression, verbal aggression, anger, or hostility against a target that is unwilling to accept the resulting physical, psychological, or relational harm.

Cyber aggression can be perpetrated by a wide range of actors, from nation states, transnational actors, and criminal organizations to small groups and individuals (Joint Chiefs of Staff 2018, I-11) against the same wide range of actors. The actual targets may include critical infrastructure (e.g., electric grids or transportation systems), private sector resources (e.g., retailers' consumer databases or banking systems), governmental and political institutions (e.g., voting systems or political party networks), the military (e.g., air defense systems or avionics 
software), social organizations (e.g., interest groups or nonprofit organizations), and individuals (e.g., financial or romantic partners).

In the case of mass-targeted (versus individual-targeted) cyber aggression, the intent often is to harm the target by denying it the use of resources by degrading, disrupting, or destroying it or by manipulating its information or information systems (Joint Chiefs of Staff 2018, II-7). The activities can directly target an adversary's cyber functions or be designed to create cascading effects in other cyber systems or physical domains (Joint Chiefs of Staff 2018, II-5). The effects can be physical, such as the destruction of equipment or digital information, or psychological, such as the loss of user confidence in a computer-based system (Borghard and Lonergan 2017, 461-2; Rosenzweig 2013, 10). More technically, cyber aggression ranges from cyber mischief (harmful but legal cyber behavior) to cyber intrusions (unauthorized access to a computer system) and cyber exploitation (where the unauthorized access is capitalized on) to cyber operations (where the system is accessed in order to leave malware ${ }^{1}$ for later use) and cyberattack (when malware is activated in order to cause damage to an opponent) (Rosenzweig 2013). Tactically, cyber aggression may include, in terms of increasing costs to aggressors, the many forms of cyber mischief to be discussed later (e.g., abusive text messages or trolling websites), distributed denial of service (DDoS) attacks² (e.g., against Trump campaign websites in 2016) and unauthorized remote intrusions via compromised user accounts (e.g., the Associated Press Twitter account in 2013), website defacement (e.g., US Army in 2015),

\footnotetext{
${ }^{1}$ In a malware attack, software infects a computer system to make it perform functions it was not intended to perform.

${ }^{2}$ In a DDoS attack, a targeted computer system is inundated with information or requests to the point that it cannot provide services to legitimate users.
} 
privileged access to internal networks for data theft (e.g., Sony in 2014), and access-dependent attacks using malware against internal networks and systems (e.g., the Stuxnet attack on the Iranian nuclear program in 2010) (Borghard and Lonergan 2017, 467; Weissbrodt 2013, 355).

It is important to note that the definition excludes cyber-enabled activities, which we define as those in which cybertechnology plays a peripheral but not fundamental role. An activity is cyber enabled when it typically occurs in the offline world without cybertechnology but in the particular instance it uses cybertechnology to accomplish its objective. For instance, buying a book on hacking from an online retailer would be a cyber-enabled act, because book buying frequently occurs in the offline world, but in this case the purchase was made online. But later using technical information gleaned from the book to access non-public areas of a computer system would be a case of cyber aggression, because cybertechnology played an essential role in the act. On the other hand, the definition of cyber aggression also includes intrusions and disruptions of non-networked (i.e., stand-alone) electronic systems requiring physical access when cybertechnology plays a fundamental role in the act. For example, the introduction of the Stuxnet worm into a stand-alone network of computers at the Iranian nuclear facility at Natanz was likely a human intelligence operation (Langner 2013). Similarly, it would define as cyber aggression (i.e., a cybercrime) illegally opening or accessing an online bank account using trash can-scavenged personally identifiable information, because it is unlikely that a bank account could be opened in person offline with the available information. While the primary objective of this essay is to define cyberterrorism and distinguish it from other forms of cyber aggression, it is important to note that behavior in cyberspace is distinct from behavior in the physical world. At the individual level, evidence suggests people 
apply a different moral standard when online that leads to more anti-social behavior including aggression. This negative behavior has been associated with the perception of greater anonymity and less external control in the networked world, which decreases the probability of the perpetrator realizing immediate consequences of cyber behavior. Because cyberspace is unbounded in time and geography, cyber aggression can be perpetrated nearly anytime from almost any location (Patri et al. 2018). Relatedly, because cyberspace is unbounded, the number of potential targets and the size of the potential audience for cyber aggression is dramatically larger than in the physical world (Smith 2012). Finally, just as intercontinental missiles enable attacks against an adversary's population without engaging the adversary's military, cyberspace makes it possible to attack a target, whether an individual, group, organization, or government, without incurring the risks associated with physical confrontations (Borghard and Lonergan 2017, 454), which, along with perceptions of increased anonymity, also increases the probability an aggressor will act.

Figure 1 offers a structure for our conceptions by presenting a typology of cyber aggression by relating the types of cyber aggressions to each other in terms of the frequency with which an aggression occurs and the potential levels of mass harm that each type of cyber aggression can cause. It offers specific types of cyber aggression ranging from frequent but annoying cyber mischief and economically damaging cybercrime to less frequent but more consequential threats to nations including cyber espionage and cyberterrorism to rare but potentially existentially harmful cyberwar (as adapted from Rosenzweig 2013). It is important to note that the boundaries between each type in Figure 1 are not fixed and definitive but are 
designed to offer a basic structure that can be used to distinguish between the cyber aggressions along two dimensions.

\section{Typology of Cyber Aggression}

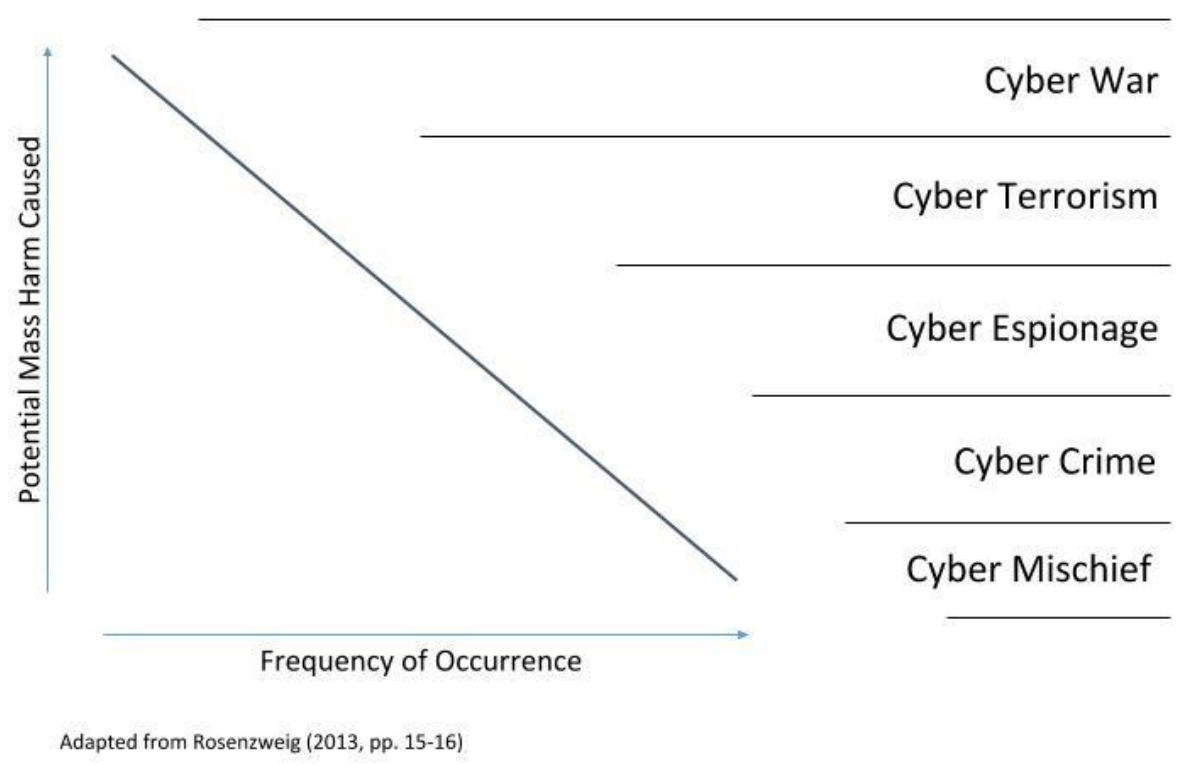

Figure 1. Typology of Cyber Aggression

The following sections expand on the typology by introducing and describing in more detail these types of cyber aggression. Each section includes brief reviews of pertinent cases that highlight features that distinguish each alternative form of cyber aggression from cyberterrorism. We begin with a review of cyberterrorism, which is the focus of this essay, to provide a basis of comparison for the other forms of cyber aggression.

\section{CYBERTERRORISM}

In a 2017 announcement about the establishment of a new United Nations (UN) Office of Counter-Terrorism, UN Secretary-General António Guterres stated that he "considers counter-terrorism and prevention of violent extremism to be one of the highest priorities of the 
United Nations to address a growing threat to international peace and security" (United Nations 2017). This high priority reflects the prevalence of terrorism around the globe. The Global Terrorism Database (GTD) counts more than 170,000 terrorist events since 1970 . These events include bombings, assassinations, and kidnappings across all regions and almost all countries. There is no widely agreed upon definition of terrorism, but some of the most prominent include:

- Alex P. Schmid, Terrorism researcher: "Terrorism refers, on the one hand, to a doctrine about the presumed effectiveness of a special form or tactic of feargenerating, coercive political violence and, on the other hand, to a conspiratorial practice of calculated, demonstrative, direct violent action without legal or moral restraints, targeting mainly civilians and non-combatants, performed for its propagandistic and psychological effects on various audiences and conflict parties" (Schmid 2011, 86).

- US Department of Defense: "the unlawful use of violence or threat of violence, often motivated by religious, political, or other ideological beliefs, to instill fear and coerce governments or societies in pursuit of goals that are usually political" (Joint Chiefs of Staff 2014).

- China draft law article 104: "any thought, speech, or activity that, by means of violence, sabotage, or threat, aims to generate social panic, influence national policy-making, create ethnic hatred, subvert state power, or split the state" (Zhou 2015). 
- United Nations description of terrorism: "criminal acts, including against civilians, committed with the intent to cause death or serious bodily injury, or taking of hostages, with the purpose to provoke a state of terror in the general public or in a group of persons or particular persons, intimidate a population or compel a government or an international organization to do or to abstain from doing any act" (United Nations Security Council Resolution 1566 [2004]).

- United States federal code: terrorism involves "violent acts or acts dangerous to human life that...appear to be intended (i) to intimidate or coerce a civilian population; (ii) to influence the policy of a government by intimidation or coercion; or (iii) to affect the conduct of a government by mass destruction, assassination, or kidnapping (Title 18 US Code §2331).

- European Union: “intentional acts...which, given their nature or context, may seriously damage a country or an international organisation where committed with the aim of: seriously intimidating a population, unduly compelling a Government or international organisation to perform or abstain from performing any act, or seriously destabilising or destroying the fundamental political, constitutional, economic or social structures of a country or an international organization" (Council of the European Union 2002).

- Global Terrorism Database: "the threatened or actual use of illegal force and violence by a non-state actor to attain a political, economic, religious, or social goal through fear, coercion, or intimidation" including two of the following three criteria: “(1) The act must be aimed at attaining a political, economic, religious, or social goal; 
(2) There must be evidence of an intention to coerce, intimidate, or convey some other message to a larger audience (or audiences) than the immediate victims; and (3) The action must be outside the context of legitimate warfare activities (START 2017).

Regardless of the definition, the common features of terrorism appear to be the illegal use of force or violence to intimidate or coerce other actors into political, social, or economic change.

\section{DEFINING CYBERTERRORISM}

Like conventional terrorism, scholars use a number of definitions of cyberterrorism (Jarvis, Macdonald, and Nouri 2014). In the most literal sense, some define it in terms of "pure" cyberterrorism, that is, a terrorist attack with a "computer as target" (Gordon and Ford 2002, 640; see also Tafoya 2011). Congressional testimony from computer scientist Dorothy E. Denning provides one of the most widely used definitions of cyberterrorism and takes the pure position:

[Cyberterrorism] is generally understood to mean unlawful attacks and threats of attack against computers, networks, and the information stored therein when done to intimidate or coerce a government or its people in furtherance of political or social objectives (Denning 2000).

Denning elaborated on her definition by stating that:

to qualify as cyberterrorism, an attack should result in violence against persons or property, or at least cause enough harm to generate fear. Attacks that lead to death or bodily injury, explosions, plane crashes, water contamination, or severe economic loss would be examples. Serious attacks against critical infrastructures could be acts of 
cyberterrorism, depending on their impact. Attacks that disrupt nonessential services or that are mainly a costly nuisance would not.

Because of the high threshold of effect, violence or harm beyond nuisance, some scholars challenge the notion that cyberterrorism can really exist. Gartzke (2013) argues that cyberattacks are not suited to fomenting terror. He writes, "No one will be happy when the power goes out or when one's bank account is locked down, but attacks of this type evoke feelings of anger, frustration, even resignation, not terror" (Gartzke 2013, 69).

Others, though, take a broader perspective on the role of cyber in terrorism by considering how "woven throughout the picture" cyber is in the act (Gordon and Ford 2002, 642):

- Symantec Security Response: "terrorism where a computer or the Internet plays an important part in the terrorism matrix [of perpetrator, place, action, tool, target, affiliation, and motivation]" (Gordon and Ford 2002, 643).

- US Army Cyber Command Fellow Jonalan Brickey: "cyberterrorism is the use of cyber capabilities to conduct enabling, disruptive, and destructive militant operations in cyberspace to create and exploit fear through violence or the threat of violence in the pursuit of political change" (Brickey 2012, 6).

In other words, there is a debate as to whether cyberterrorism is limited only to acts against computer systems or if it includes acts in which computer systems play a substantial role. For instance, in the terrorism matrix referenced by Gordon and Ford (2002), if using the "pure" cyberterrorism definition, an act would only be cyberterrorism if a computer function were the target (e.g., DDoS or malware attack). On the other hand, under the broader 
conception, an act would be cyberterrorism if a computer function were not the target but played a substantial role as a tool of the attack or in the action of the attack (e.g., posting videos of beheadings on social media).

With conventional definitions of terrorism and this debate in mind, we define cyber terrorism as a threatened or actual computer-mediated act consequentially conducted through electronic networks by subnational actors to intimidate or coerce governments or people in order to achieve the perpetrator's political, economic, or social objectives. This definition uses a narrower conception. In the examples above, a malware attack conducted for political, economic, or social objectives would be an act of cyberterrorism (computer function as target), but posting videos of politically motivated beheadings on social media would not (computer function a tool of attack only). In particular, this definition includes cases where cyber functions are the primary target of the attack and, recalling the discussion related to cyber aggression more broadly, cases where cybertechnology plays a consequential or essential role in the act such that the act exists only or primarily because of its cyber nature or that the conduct of the act requires expertise in cybertechnology beyond that of the typical user of cybertechnology. Cyberterrorism does not have to involve direct physical force or violence against people or property, but it or its consequences generate comparable fear. Although it can be intended to cause physical or psychological effects, like conventional terrorism it is primarily intended to cause psychological effects on a broad audience. As indicated in Figure 1, cyberterrorism can cause medium-high levels of harm but has a low frequency of occurrence. It employs cyber exploitation and cyber operations but can pursue its objectives using any of the forms of cyber attack. 


\section{EXAMPLES OF CYBERTERRORISM}

In 2016, a Kosovar hacker was sentenced to 20 years in US prison for stealing the personally identifiable information of 1,300 US military members from a corporate server and delivering the information to the Islamic State of Iraq and the Levant (ISIL), a jihadist terrorist organization, with the intent of inciting attacks against the military members (US Department of Justice 2016). In regard to the operation, an ISIL operative tweeted a threatening message stating "we are in your emails and computer systems, watching and recording your every move, we have your names and addresses, we are in your emails and social media accounts, we are extracting confidential data and passing on your personal information to the soldiers of the khilafah, who soon with the permission of Allah will strike at your necks in your own lands!" In 2015, a group of hackers identified only as 3301 broke into the computer system of Planned Parenthood Federation of America, a women's healthcare provider that offers abortion services, and stole hundreds of employee names and email addresses that it later published on its private website (Shively 2015). Similarly, an executive of a chain of reproductive healthcare clinics in Texas noted that following her testimony regarding abortion to the state Legislature attacks on her organization's computer system surged to the point of shutting the system down (Grant 2017). In 2013, the Syrian Electronic Army, a pro-regime hacking group, claimed responsibility for hijacking a number of high-profile, media-owned Twitter accounts and publishing several pro-regime news tweets, including threats toward Jews, neighboring countries, and opponents of the regime (BBC News 2013; Fitzpatrick 2013).

\section{DISTINGUISHING CYBERTERRORISM FROM CONVENTIONAL TERRORISM}


Like conventional terrorism, cyberterrorism is intended to intimidate or coerce others into political, social, or economic change. Also, like conventional terrorism, it can cause either physical or psychological harm, although its primary objective is psychological. Unlike conventional terrorism, cyberterrorism attempts to achieve its objectives by disrupting the target's cyber functions or manipulating its data. It employs cyber exploitation and cyber operations but can pursue its objectives using any of the forms of cyber attack.

Some may argue that what we call cyberterrorism is really just conventional terrorism conducted by cyber means, something akin to terrorist attacks on ice pick factories being deemed "ice pick terrorism" (Gordon and Ford 2002, 645). We disagree and believe that what we identify here is a distinct form of aggression that uses different actors, tools, and defensive responses than conventional terrorism. As defined here, both perpetrators of and defenders against cyberterrorism require expertise in and tools for cybertechnology beyond the skills and tools possessed by the typical cybertechnology user. Beyond the obvious difference in reliance on cyber functions, attribution of cyberterrorism can be much more difficult than attribution of conventional terrorism because the anonymity of cyberspace makes identifying harmful information nearly impossible (Borghard and Lonergan 2017, 457, 459). Without proper attribution, categorizing an event, determining intent, and, more importantly, developing responses are difficult (Borghard and Lonergan 2017, 456). For instance, the Islamic State's Cyber Caliphate claimed credit for an attack on a French TV station in 2015. This was immediately labelled an Islamic State attack but later reconsidered when French authorities concluded it was actually the result of Russian hacking (Corera 2016). Further, the ability of hackers to maintain anonymity and their relative safety from physical and legal responses by 
attacking from remote locations may democratize and even encourage much greater levels of cyberterrorism relative to conventional terrorism. As well, cyber weapons can dramatically expand the pool of direct victims (e.g., the citizens of an entire region whose power grid has been disrupted), and, "like nuclear weapons, [they] enable governments [and other attackers] to target adversary populations while bypassing the latter's military forces" (Borghard and Lonergan 2017, 454). More profoundly, unlike conventional terrorism, where each act can be viewed in isolation, cyberattacks can escalate quickly setting off a chain reaction, where "events cascade faster and deeper" (Taleb 2008; see also Joint Chiefs of Staff 2018, II-5).

Now that we have reviewed the fundamental dimensions of cyberterrorism and distinguished it from conventional terrorism, the following sections provide a review of the other types of cyber aggression, starting with cyber mischief, the least harmful type, in an effort to clarify the proposed definition of cyberterrorism.

\section{CYBER MISCHIEF}

In 1787 in Federalist No. 10, one of the most acclaimed political essays ever written, author James Madison warned against the "mischiefs of faction," or the tendency of groups within the political system to pursue their interests at the expense of others' or of the greater interest. In modern times, mischief is thought of as bad, troublemaking, or annoying behavior that usually causes limited or minimal harm. In particular, mischief is associated with irresponsible and even childish acts such as pranks and recreational behavior that are engaged in to relieve boredom, find entertainment, or retaliate for a perceived wrong (Thacker and Griffiths 2012). With over half the world's population using the internet for about six hours 
each day by some estimates (We Are Social, 2018, intro), there is ample opportunity for mischief in the cyber realm.

\section{DEFINING CYBER MISCHIEF}

Bad behavior thrives in the networked world, and researchers have identified a number of cyber activities that fall into the category of cyber mischief. Individual perpetrators may harass others by mobile phone calls, text messages, emails, or chat room messages. They may publicly expose or "out" their targets to, or exclude them from, social networks. Cyber mischief makers commonly referred to as "trolls" may litter websites with provocative messages for their or others' entertainment (Bishop 2013, 2), while others may masquerade as someone else to shame or embarrass them by spreading harmful information or acting inappropriately. The messages conveyed through cyber mischief range from name calling and social or political provocation to threatening physical violence and death; from making unwelcomed demands to damaging or ending platonic or romantic relationships and revealing private sexual acts (Smith 2012).

Groups, organizations, and nations can also perpetrate cyber mischief. Cyber mischief at the macro level usually takes the form of information warfare, which is intended to disseminate information or propaganda through regular communication channels to manipulate or demoralize an enemy or even influence the international system (Singer and Brooking 2018). Some scholars claim that social media have been weaponized into a form of information warfare called "LikeWar," which is designed to motivate members of large social networks to spread negative emotions, especially anger, to other members of the network (Singer and Brooking 2018, 162). 
Informed by this range of activities and put in terms of the typology of cyber aggression presented here, we define cyber mischief as a computer-mediated act consequentially conducted through electronic networks to harm intentionally but lawfully another actor that is motivated to avoid the harm. Cyber mischief may target individuals, groups, and all types of governmental and non-governmental organizations. Its effects may be psychological and relational. Although it is primarily perpetrated by individuals, groups and even nations do engage in cyber mischief in pursuit of their objectives. The reach and anonymity of the internet and the ease of access to it provide numerous opportunities for annoying behavior. There are many avenues for cyber mischief beyond general internet network access including social media sites such as Facebook, Twitter, Instagram, Sina Weibo, and VK, and instant messaging apps such as WhatsApp, QQ, WeChat, Telegram, and Viber. Moreover, these access points typically are available 24 hours a day every day. Due to low costs of entry related to ease of access and lack of legal liability, cyber mischief is ubiquitous and the most prevalent form of cyber aggression.

\section{EXAMPLES OF CYBER MISCHIEF}

There are widespread reports of cyber mischief at the individual level. For example, a Pakistani social activist became a target for social media and email harassment temporarily forcing her offline following a protest she organized related to women's health (Toppa 2017). Social media users outed marchers at a highly publicized white nationalist demonstration in the United States in 2017 by posting pictures of them at the march on social media in an attempt to shame them publicly, which even led some marchers to lose their jobs (Melendez 2017). In another case, a fan of a reality television show contestant was trolled, including allegations she 
was a drug dealer, and later became a victim of masquerading, in which the perpetrator created a false Facebook page in her name suggesting she was a pedophile, following her online posts in support of the contestant (McCarthy 2013).

Cyber mischief at the macro level appears to be accelerating, with some analysts particularly expressing concern about its effects on the international system. Russia has increased its information warfare efforts in recent years including extensive disinformation operations in Germany related to immigration issues as well as during elections in France and the United States (Rutenberg 2017). For example, in the lead up to the 2016 US presidential election, Russian assets used "sockpuppets" and bots to write hundreds of social media posts each day in order to take over conversations, spread disinformation, and sow discord that would benefit the Russian government (Singer and Brooking 2018, 111). In the end, Singer and Brooking $(2018,144)$ estimate this virtual "blitzkreig" generated 2.2 million election-related tweets that were delivered 454.7 million times in the final three months of the election, while Facebook announced that 126 million users saw Russian disinformation during the 2016 election. The Islamic State has also widely engaged in cyber mischief in the form of information warfare. Scholars have assessed its online strategies as consisting of a core network of social media users who produce a disciplined message that is disseminated worldwide (Siegel and Tucker 2018). The group produced a highly choreographed social media campaign that was amplified by a large network of Twitter bots to post hundreds of thousands of propaganda statements, selfies, actual firefights, and beheadings of resistors, which beyond their propaganda value were persuasive enough to recruit around 30,000 individuals who had never met a member of ISIS to travel to join them (Singer and Brooking 2018, 149). 


\section{DISTINGUISHING CYBER MISCHIEF FROM CYBERTERRORISM}

Cyber mischief primarily can be distinguished from cyberterrorism in that the harmful act involved in cyber mischief is legal, while acts of cyberterrorism are illegal. As indicated in Figure 1, cyber mischief occurs very frequently and the consequences are usually very low, while cyberterrorism has a near-opposite frequency-harm profile, occurring at a very low rate but with medium-high levels of harm when it does occur. In some cases, such as masquerading, cyber mischief is intended to manipulate data related to a target, but cyber terrorism can target an adversary's data or cyber functions. Both are forms of cyber attack with the objective of inflicting psychological harm, and it is important to note that cyber mischief often seeks to harm others and, like cyber terrorism, the motivation may be political, social, or economic. Like cyber terrorism, both individuals and groups or states can perpetrate cyber mischief.

\section{CYBERCRIME}

Pioneering social scientist Emile Durkheim claimed "Crime is not only observed in most societies of a particular species, but in all societies of all types" concluding that "a society exempt from it is utterly impossible" (1895/2014, p. 60). In modern times, a crime is the violation of a criminal statute. These statutes can be found in criminal and other legal codes and usually cover offenses against persons, property, public safety, and financial arrangements. These can be legal codes for an entire nation or for a section of a nation such as a state within the United States or prefecture within Japan. 


\section{DEFINING CYBERCRIME}

Cyberspace has long been recognized as a conducive environment for criminal activity, and crime continues to thrive there (Kubic 2001). As FBI Director James Wray stated in a 2018 cyber security speech, "Transnational crime groups, sexual predators, fraudsters, and terrorists are all transforming the way they do business as technology evolves. Huge swaths of these crimes have a digital component or occur almost entirely online. And new technical trends are making the investigative environment a lot more complex" (Wray 2018). Academic and policy experts have defined cybercrime in a variety of ways.

- Austria: Cyber crime comprises illegal attacks from cyberspace on or through ICT [information and communication technology] systems, which are defined in penal or administrative laws. The term therefore covers all criminal offences committed with the aid of information technologies and communications networks and also encompasses Internet crime (Federal Chancellery of the Republic of Austria 2013, 21).

- Qatar: Misconduct or crime committed using technology. Examples of cyber crime may include illegal access to systems or information, fraud, identity theft, or content-related offenses such as spam (Ministry of Information and Communications Technology 2014, 23).

- New Zealand: A criminal act that can only be committed through the use of ICT or the Internet and where the computer or network is the target of the offence. This is regardless of what the criminal goal is - whether political or financial gain, espionage or any other reason... Cyber-enabled crime is any criminal act that 
could be committed without ICT or the Internet, but is assisted, facilitated or escalated in scale by the use of technology (New Zealand Department of the Prime Minister and Cabinet 2015, 4).

- United Nations: cybercrime can be described as having cyber-dependent offences, cyber-enabled offences and, as a specific crime-type, online child sexual exploitation and abuse. Cyber-dependent crime requires an ICT infrastructure and is often typified as the creation, dissemination and deployment of malware, ransomware, attacks on critical national infrastructure...and taking a website offline by overloading it with data (a DDOS attack). Cyber-enabled crime is that which can occur in the offline world but can also be facilitated by ICT... Child Sexual Exploitation and Abuse includes abuse on the clear internet, darknet forums and, increasingly, the exploitation of selfcreated imagery via extortion - known as "sextortion" (United Nations Office on Drugs and Crime n.d.).

- Council of Europe: action directed against the confidentiality, integrity and availability of computer systems, networks and computer data as well as the misuse of such systems, networks and data (Council of Europe 2001, 1).

These definitions suggest a wide variety of types and levels of cybercrime. Although cyberspace can facilitate conventional, offline crimes such as identity theft, transaction fraud, and illegal drug sales, there are a number of common cybercrimes that occur only or primarily because of infrastructure in the cyber world. In the most basic form of cybercrime, unauthorized intrusions include "hacking," accessing a computer system to gain knowledge 
about how the system works with no intent to cause damage or disruption, and "cracking," accessing a computer system with the intent to cause damage or disruption (Smith, Yurick, and Doss 2002). Ransomware is a form of extortion that uses malware to make a computer or its contents inaccessible until the victim pays a ransom. Digital piracy involves stealing computer software and other intellectual property stored in digital form such as movies and music. Cyber industrial or economic espionage targets firms' trade secrets for the benefit of a foreign entity or anyone other than the owning firms. Online child sexual exploitation takes place in social media, chat rooms, child pornography websites, online groups, peer-to-peer file sharing, and bulletin board systems.

With these definitions and the typology of cyber aggression in mind, we define cybercrime as a computer-mediated act consequentially conducted through electronic networks to commit a criminal offense against other persons, property, public safety, or financial arrangements for individual or economic gain. Due to its wide range of potential activities, cybercrime traverses many of the categories of cyber aggression. For instance, like cybercrime, cyberespionage and cyberterrorism are also subject to criminal statutes in many jurisdictions. Cybercrime may be intended to disrupt its target or manipulate its data (e.g., ransomware). Its effects may be physical or psychological (e.g., online child sexual exploitation). Technically, it may be conducted via cyber exploitation (e.g., cyber espionage) or attack (e.g., ransomware), and it may use any of the tactics from compromised accounts (e.g., hacking) and website defacement (e.g., cracking) to privileged access (e.g., digital piracy) and an access-dependent attack (e.g., cracking). 


\section{EXAMPLES OF CYBER CRIME}

There have been several large-scale cybercrimes in recent years. In 2017, hackers exploited a website vulnerability to steal private information-including addresses, birthdates, social security numbers, driver's license numbers, and tax IDs-on more than 145 million individuals from Equifax, a credit reporting agency (Fung 2018). That same year, hackers infected the UK's National Health Services (NHS) computer system with ransomware named "WannaCry." The malware was delivered by email and locked down as many as 300,000 NHS computers with the hackers demanding money to unlock the infected units. In 2015 , one group of hackers stole private information that yielded more than $\$ 900$ million from more than 100 banks around the world using malware and impersonating banking staff to make fraudulent transfers. Another group stole personal information from millions of J. P. Morgan Chase customers and sold it to a network of criminal associates. This group also accessed companyrelated information that allowed them to trade profitably in the financial markets on what amounts to insider information. In 2014, hackers believed to be associated with North Korea stole sensitive and proprietary data from Sony Pictures and attempted to blackmail the entertainment company into cancelling the release of a movie that cast the country's leader in a negative light (Elsom 2017). Cybercrime can also occur on a much smaller scale. In 2015, an individual was convicted of stealing computer code for making high-frequency financial trades from his employer and using the "proven money-making system" in his personal trading account (US Department of Justice 2015). In 2001, another individual was found guilty of conducting cyber attacks in revenge for a rejected job application on a waste management system in Australia that caused a spill of more than two hundred thousand gallons of raw 
sewage into local parks and rivers and onto the grounds of a hotel more than seven miles away (Sayfayn and Madnick 2017).

Finally, economic cyber espionage, which will be discussed in more detail in the next section, can be related to government cyber espionage. Five Chinese military members were indicted in 2014 for maintaining unauthorized access to the computer systems of several US corporations and stealing information that would be valuable to the companies' Chinese competitors (US Department of Justice 2014). While primarily intended for economic gain, the involvement of members of the Chinese military makes it reasonable to infer there may have been political or military objectives making this, therefore, cyber espionage.

\section{DISTINGUISHING CYBERCRIME FROM CYBERTERRORISM}

Cybercrime can primarily be distinguished from cyberterrorism in that its main objective is personal or economic gain versus political, social, or economic change. As indicated in Figure 1, cybercrime occurs very frequently and the consequences are usually low, while cyberterrorism has a near-opposite frequency-harm profile, occurring at a very low rate but with medium-high levels of harm when it does occur. Consequently, individuals are much more likely to be the victim of a cybercriminal than a cyberterrorist. Unlike cyberterrorism where the perpetrator either disrupts the target's cyber functions or manipulates its data, that may or may not be the case in a cybercrime. The objective of cyberterrorism is to create psychological harm, while cybercrime may include either physical, psychological, or relational harm.

Cyberterrorism is a form of cyberattack, but cybercrime may range from cyber exploitation to cyberattack. Both cyberterrorism and cybercrime use the full range of potential tactics. 


\section{CYBER ESPIONAGE}

In his classic $5^{\text {th }}$ century BCE military treatise, Art of War, Sun Tzu dedicated an entire chapter to "the use of spies." In chapter 13 he noted: "Thus, what enables the wise sovereign and the good general to strike and conquer, and achieve things beyond the reach of ordinary men, is foreknowledge." This suggests that nations have been gaining foreknowledge on their enemies' dispositions-engaging in espionage-for more than two millennia. Fundamentally, espionage is about collecting the private information of another actor (Maurer 2018, 459). Espionage can either be physical in nature, characterized by human intelligence, or technical in nature, characterized by signals intelligence (Rid 2012).

Espionage, whether in the physical or technical domain, is often categorized as either governmental espionage, which is the theft of secrets for military or political advantage, or economic espionage, which is the theft of intellectual property for commercial gain (Lewis 2010, 2; Rosenzweig 2013, 23). Governmental espionage is "an expansion of traditional efforts to collect information on an opponent's intentions and military capabilities" (Lewis 2010, 2). On the other hand, economic espionage is "where foreign governments, companies and citizens steal intellectual property and confidential business information" (Lewis 2010, 1-2).

The US adopted its current government-espionage law in 1917 shortly after entering World War I, and many countries take similar approaches to protecting their state secrets. The Espionage Act, as embodied in chapter 37 of the US Code, makes it illegal to gather, transmit, or lose defense information (18 USC §793); gather or deliver defense information to aid a foreign government (18 USC §794); photograph or sketch defense installations (18 USC §795); or disclose classified or restricted national security-related information (18 USC §798). On the 
other hand, industrial or economic espionage, according to the Economic Espionage Act of 1986, makes it illegal to target or acquire trade secrets for the benefit of a foreign entity (Title 18 U.S.C. §1831) or anyone other than the owner (Title 18 U.S.C. §1832). Because the primary objective of economic espionage is commercial gain, in our view it is properly classified as a cybercrime as noted in that section above.

\section{DEFINING CYBER ESPIONAGE}

The methods and weapons of espionage could not help but change over the expanse of millennia of conflict, but some of the most profound changes have occurred since the advent of the digitally networked world and mass information storage (Rosenzweig 2013). Senior leadership within the U.S. Department of Defense have noted both military and civilian computer networks are probed "thousands of times" every day (Lynn 2010, 97). Given the prevalence of these cyber intrusions, a number of researchers have offered specific definitions of cyber espionage:

- According to computer scientists Uma and Padmavathi $(2013,393)$, "It is the act or practice of obtaining secret information of individuals, groups and governments for gaining benefits of their own using illegal abuse methods so as to obtain information without permission of the holder."

- Former US government homeland security official Rosenzweig $(2013,23)$ defines it as, "Exploitation of a system for the purpose of securing data and information that is intended to be kept confidential."

- The US Defense Security Service (n.d., 1) defines cyber espionage as, "The act of obtaining, delivering, transmitting, communicating, or receiving information about 
the national defense using cyberspace with an intent, or reason to believe, that the information may be used to the injury of the United States or to the advantage of any foreign nation."

- The Tallinn Manual (Schmitt 2013, 193) on the application of international law to cyber conflict defines it as "Any act undertaken clandestinely or under false pretenses that uses cyber capabilities to gather (or attempt to gather) information with the intention of communicating it to [an] opposing party."

- Professor of strategic studies Thomas Rid $(2012,20)$ indicates it is an "attempt to penetrate an adversarial computer network or system for the purpose of extracting sensitive or protected information."

- Professor of law David Weissbrodt $(2013,371)$ says it is the "intentional use of computers or digital communications activities in an effort to gain access to sensitive information about an adversary or competitor for the purpose of gaining an advantage or selling the sensitive information for monetary reward."

Informed by these definitions and put in terms of the typology of cyber aggression, we define cyber espionage as a computer-mediated act consequentially conducted through electronic networks to gain unauthorized access to the confidential military or political information of another actor. Espionage, whether cyber or conventional, is the act of stealing the private information of another actor in order to understand the capabilities and aspirations of that actor (Borghard and Lonergan 2017, 480; Maurer 2018). The aggressor's intent is to remain undetected and unknown by the target and other actors so the aggressor can continue to have access to the target's information. Cyber espionage, then, is not intended to disrupt the 
target or manipulate its data in any way (JCS 2018), nor is it intended to cause any physical or psychological effects (Borghard and Lonergan 2017). It is cyber exploitation carried out via unauthorized access to the target's computer functions through activities such as hacked user accounts or privileged access to internal networks (Borghard and Lonergan 2017; Rosenzweig 2013).

It is important to be clear about what distinguishes an act of cyber espionage from an act of conventional espionage, sometimes referred to as physical espionage. While Weissbrodt notes cyber espionage is "merely another form of espionage" $(2013,371)$, he also highlights several important distinctions between conventional and cyber espionage. For instance, he notes that unlike conventional espionage, cyber espionage can be conducted from outside the targeted country or organization. He also notes that it is more "intrusive" than conventional espionage because it can reap vast amounts of data (e.g., the difference between taking out a few books worth of information versus an entire library) and because it gives non-state actors the ability to conduct espionage $(2013,371)$.

\section{EXAMPLES OF CYBER ESPIONAGE}

The earliest known act of government-related cyber espionage occurred around 1968 when an East German spy was caught intruding into the computers of IBM's West German subsidiary (Warner 2012). Although information on the 1968 case is limited, much more is known about a case detected in 1986 involving computers at Lawrence Berkeley National Laboratory (LBNL) (Stoll 1988). It involved a computer network manager who discovered an unauthorized remote intrusion in LBNL computers that was similar to intrusions into US military bases where the hacker was looking for information with searches for words like "nuclear" and 
"SDI," a reference to a missile defense system initiated in the United States in the early 1980s.

Investigators later discovered that the intruder was a West German who was selling the information to the Soviet Union's intelligence services presumably for military purposes.

Investigators later detected a long-term intrusion into US defense agencies that

occurred from 1998 to 1999 (Rid 2012). Moonlight Maze was a likely Russian operation in which actors intruded into computer systems of NASA, the Department of Energy, the Department of Defense, and several US-based research universities. Evidence suggests the intruders accessed thousands of classified documents including maps of US military bases, troop configurations, and designs for military hardware and weapons.

Cybersecurity specialists discovered malware in 2012 primarily being used in the Middle East. The software, most popularly known as "Flame," records audio, screenshots, keyboard activity, and network traffic that are sent to command and control servers around the world and, in turn, receives instructions back from the servers. Some investigators have associated Flame with preparations by the US and Israel for attacks on Iran's nuclear program, which they fear is being developed with a military objective (Weissbrodt 2013, 380).

Most recently, the US Department of Justice issued indictments against Iranian-based hackers who, starting in 2013, targeted research and intellectual property at hundreds of US and foreign universities as well as multiple US companies and government agencies and the United Nations (Nakashima and DeYoung 2018). The hackers stole more than 31 terabytes of data estimated to be worth $\$ 3.4$ billion on behalf of Iran's Islamic Revolutionary Guard (IIRG). Analysts believe the information is being used by the IIRG to advance its own research and weapons development. 
The previous examples relate to national defense, but cyber espionage can also be designed to gain political advantage. Numerous media outlets reported intrusions into Democratic National Committee (DNC) computer systems prior to the 2016 US presidential election. A report by the FBI indicates Russian civilian and military intelligence services gained access to the systems that allowed them to "exfiltrate" sensitive email from several senior party members. Controversial content of some of the email were later publicly disclosed through the media, which raised questions about foreign influence on the election (FBI-NCCIC 2016).

\section{DISTINGUISHING CYBER ESPIONAGE FROM CYBERTERRORISM}

Cyber espionage can primarily be distinguished from cyberterrorism in that it is intended to be and remain surreptitious, while cyberterrorism is intended to be apparent to a broad, public audience. So it is not intended to do immediate damage, either physical or psychological, but it is intended to steal information only (Weissbrodt 2013). Both cyberterrorism and cyber espionage occur at low rates but can cause medium-high damage when they do occur. It is cyber exploitation and does not reach the level of a cyber operation or attack as cyber terrorism and the other forms of cyber aggression do. It is important to note, though, that some of the mechanisms used for cyber espionage can be "upgraded" to cause immediate damage to targeted systems (Weissbrodt 2013). This potential suggests that a transition to cyberterrorism and other forms of cyber aggression can follow closely from cyber espionage. Tactically, while cyber terrorism can be carried out using DDoS attacks or any of the four types of unauthorized access, cyber espionage is typically conducted using either unauthorized access via hacked user accounts or privileged access. In many ways, then, cyber espionage is distinct from cyber terrorism and the other forms of cyber aggression. 


\section{CYBERWAR}

Due to its brutal and consequential nature, war has drawn considerable attention across vast swaths of time, geography, and people. US Civil War general William Tecumseh Sherman succinctly captured its nature by declaring to the Michigan Military Academy class of 1879 that "war is hell." Not surprisingly, then, those who think deeply about war have taken a variety of approaches to understanding it. War has been defined in socio-political, legal, and quantitative terms, just to name a few. In the socio-political realm Clausewitz (1976) defined war as "an act

of violence intended to compel our opponents to fulfill our will," while Johnson (1935) defined it as "armed conflict between population groups conceived of as organic unities, such as races or tribes, states or lesser geographic units, religious or political parties, economic classes." Legal definitions of war include Wright's (1942) "the legal condition which equally permits two or more hostile groups to carry on a conflict by armed force" and Grotius' (2012) "the condition of those contending by force." Finally, Singer and Small (1972) attempt to define war more precisely through quantification by suggesting that it is a series of events that results in at least 1000 battle deaths, that has been prepared and/or maintained by large-scale social organizations, and that is legitimized as a duty and not a crime by an established governmental organization. Regardless of the definition, there seems to be a common theme in definitions of war indicating it is at least organized inter-group violence carried out on a large scale.

\section{DEFINING CYBERWAR}

In terms of warfighting strategies, cyberwar may include conventional objectives of war such as attrition, denial, decapitation, intimidation, punishment, and manipulation of risk 
(Borghard and Lonergan 2017, 472-478). But there is vast disagreement on what exactly cyberwar is.

- US: Cyber Warfare is cyber attacks that are authorized by state actors against cyber infrastructure in conjunction with a government campaign (Giles and Hagestad 2013, 4).

- Russia: Combat actions in cyberspace are cyber attacks carried out by states, groups of states, or organised political groups, against cyber infrastructure, which are part of a military campaign (Giles and Hagestad 2013, 4).

- Austria: Cyber war refers to acts of war in and around virtual space with means which are predominantly associated with information technology. In a broader sense, this implies the support of military campaigns in traditional operational spaces - i.e. ground, sea, air and outer space - through measures taken in the virtual space. (Federal Chancellery of the Republic of Austria 2013, 22).

- RAND Corporation: the actions by a nation-state or international organization to attack and attempt to damage another nation's computers or information networks through, for example, computer viruses or denial-of-service attacks (RAND n.d.).

- National Security Expert Richard A. Clarke: actions by a nation-state to penetrate another nation's computers or networks for the purposes of causing damage or disruption (Clarke and Knake 2010, 6).

- US Joint Chiefs of Staff speak of offensive cyberspace operations: intended to project power in and through foreign cyberspace [by targeting] adversary 
cyberspace functions or [creating] first-order effects in cyberspace to initiate carefully controlled cascading effects into the physical domains to affect weapon systems, command-and-control processes [C2], and other militarily valuable targets' C2 processes, logistics nodes, high-value targets, etc. (Joint Chiefs of Staff 2018, II-5).

With these definitions in mind and put in terms of the typology of cyber aggression, we define cyberwar as a computer-mediated act consequentially conducted through electronic networks by a nation-state to compel an adversary to comply with the aggressing nation-state's will. Broadly speaking, this includes denying an adversary the use of resources by degrading, disrupting, or destroying a target or manipulating an adversary's information or information systems (Joint Chiefs of Staff 2018, II-7). Its effects may be physical, psychological, or relational. Technically, it may be conducted via cyber exploitation (e.g., cyber espionage) or attack (e.g., ransomware), and it may use any of the tactics from compromised accounts (e.g., hacking) to privileged access (e.g., digital piracy) and an access-dependent attack (e.g., ransomware).

\section{EXAMPLES OF CYBERWAR}

A general premise of cyberwar analysts is that the international system has yet to experience a true cyberwar. Perhaps brought about by consequential cyberattacks against the nations of Estonia, Georgia, and Ukraine thought perpetrated by Russia (Tamkin 2017), though, policy-makers and scholars alike have been introduced to the idea that cyber conflict could kill humans rather than just infect computers (Rosenzweig 2013, 2). For example, a June 2017 attack on Ukraine not only disrupted a number of Ukrainian and global businesses but also forced manual radiation monitoring at the Chernobyl nuclear power plant and the cancellation 
of surgical procedures at several hospitals in the US state of Pennsylvania (Perlroth, Scott, and Frenkel 2017). According to some information technology experts, the 2017 WannaCry ransomware attack on the UK's National Health Services computer system could have killed patients if that had been the objective of the attackers (Donnelly 2018). More broadly, there are at least two cyber attacks known to have caused substantial physical damage to industrial operating equipment. In 2010, the Stuxnet malware infected software that controlled centrifuge rotors and enrichment cascades at an Iranian uranium enrichment facility. The malware modified the operation of the equipment ultimately causing physical damage to it. In 2014 attackers used a spear phishing campaign to gain access to a German steel maker's mill control system. The access allowed the attackers to prevent a blast furnace from shutting down causing "massive damage" according to the German Federal Office for Information Security (BBC News 2014). Regardless of the occurrence or not to date of instances of cyberwar, there is evidence that many states are preparing to use cyber weapons as a part of any future conflict (Rosenzweig 2013, 44).

\section{DISTINGUISHING CYBER WAR FROM CYBERTERRORISM}

Perhaps the most difficult distinction to make is between cyberwar and cyberterrorism. The main distinction between cyberwar and cyberterrorism is the type of actor. Traditionally, nation-states perpetrate war, while non-state actors perpetrate terrorism. Otherwise, as indicated in Figure 1, the scale of potential harm for terrorism is lower than for war, which can in extreme cases be existential, while cyberterrorism occurs much more frequently than cyberwar. Like cyberterrorism, cyberwar is intended to disrupt the target's cyber functions or manipulate its data. It can cause either physical or psychological harm. It employs cyber 
exploitation and cyber operations but can pursue its objectives using any of the forms of cyber attack.

\section{CONCLUSION: IDENTIFYING CYBERTERRORISM}

This essay proffers a theoretically informed and operationally useful definition of cyberterrorism: a threatened or actual computer-mediated act consequentially conducted through electronic networks by subnational actors to intimidate or coerce governments or people in order to achieve the perpetrator's political, economic, or social objectives. Like conventional terrorism, cyberterrorism is intended to intimidate or coerce others into political, social, or economic change. Also, like conventional terrorism, its primary objective is to cause psychological harm. Unlike conventional terrorism, though, cyberterrorism attempts to achieve its objectives by disrupting the target's cyber functions or manipulating its data. We argue that cyberterrorism is a distinct form of terrorism that uses different actors, tools, and defensive responses than conventional terrorism. As defined here, both perpetrators of and defenders against cyberterrorism require expertise in and tools for cybertechnology beyond the skills and tools possessed by the typical cybertechnology user. Attribution of cyberterrorism can be difficult if not impossible (Borghard and Lonergan 2017, 457, 459), which makes developing a response difficult (Borghard and Lonergan 2017, 456). Further, due to the ability of hackers to maintain anonymity as well as the relative safety from physical and legal responses they achieve by attacking from remote locations, cyberterrorism can be much more appealing than conventional terrorism possibly democratizing, and even encouraging, more cyberterrorism. 
Cyberterrorism is also distinct from the other types of cyber aggression. Table 1 summarizes a number of pertinent characteristics of each form of cyber aggression to facilitate comparisons. It shows the harms to victims of cyberterrorism, the broader public, are primarily psychological, while the harms to victims of the other types of cyber aggression range from primarily physical (cyber espionage or stealing information) to physical, psychological, and relational (cyberwar). It indicates cyberterrorism typically targets governments and groups, as does cyber espionage; while cyber mischief targets individuals, groups, and governments; cybercrime typically targets individuals and groups; and cyberwar targets governments. On the other hand, the perpetrators of cyberterrorism are subnational actors, including individuals, as are most perpetrators of cyber mischief and crime, but cyberwar is perpetrated by nationstates. Like cyberwar and cyber mischief, cyberterrorism is a public act, while cybercrime may be public or surreptitious and cyber espionage is surreptitious. With low frequency but medium to high potential mass harm, as indicated in Figure 1, the expected harm from cyberterrorism is substantial relative to cyberwar, which is rare to nonexistent but with high potential harm, and the other more frequent but less harmful cyber aggressions. Finally, the table indicates that cyberterrorism, along with cyber espionage and crime, are illegal, while cyberwar and cyber mischief are not. 


\begin{tabular}{|c|c|c|c|c|c|c|}
\hline$\frac{\text { CYBER- }}{\text { WAR }}$ & $\begin{array}{l}\text { HARMS } \\
\text { physical, } \\
\text { psychological, } \\
\text { relational }\end{array}$ & $\frac{\text { TARGETS }}{\text { govt }}$ & $\frac{\text { AGGRESSOR }}{\text { nation-state }}$ & $\frac{\text { PUBLIC? }}{\text { yes }}$ & $\frac{\text { FREQ/HARM }}{\text { rare/high }}$ & $\frac{\text { LEGAL? }}{\text { yes }}$ \\
\hline TERRORISM & $\begin{array}{l}\text { primarily } \\
\text { psychological }\end{array}$ & govt, groups & subnational & yes & low/med-high & no \\
\hline ESPIONAGE & physical & govt, groups & $\begin{array}{l}\text { nation-state, } \\
\text { subnational }\end{array}$ & no & low/med-high & no \\
\hline CRIME & $\begin{array}{l}\text { physical, } \\
\text { psychological }\end{array}$ & $\begin{array}{l}\text { groups, } \\
\text { individuals }\end{array}$ & $\begin{array}{l}\text { primarily } \\
\text { subnational }\end{array}$ & yes/no & high/low & no \\
\hline MISCHIEF & $\begin{array}{l}\text { psychological, } \\
\text { relational }\end{array}$ & $\begin{array}{l}\text { govt, groups, } \\
\text { individuals }\end{array}$ & $\begin{array}{l}\text { primarily } \\
\text { subnational }\end{array}$ & yes/no & high/very low & yes \\
\hline
\end{tabular}

This essay has described and defined the emerging role of cybertechnology in conventional forms of aggression, in particular, mischief, crime, espionage, and war relative to terrorism. Although these activities often encroach on each other-for example, crime, espionage, and terrorism are almost always subject to criminal statutes in countries - the concepts are distinct enough and there are enough dimensions to each to classify events with confidence much of the time. Figure 2 presents a decision tree that can be used to classify cyber activities. It shows how a cyber activity can be classified in terms of the typology of cyber aggression presented in Figure 1 starting on the left with a determination of the cyber nature of an activity then following through the tree to the right with affirmative responses culminating in a classification of cyberterrorism or branching off/down with a negative response to other classes of cyber aggression. 


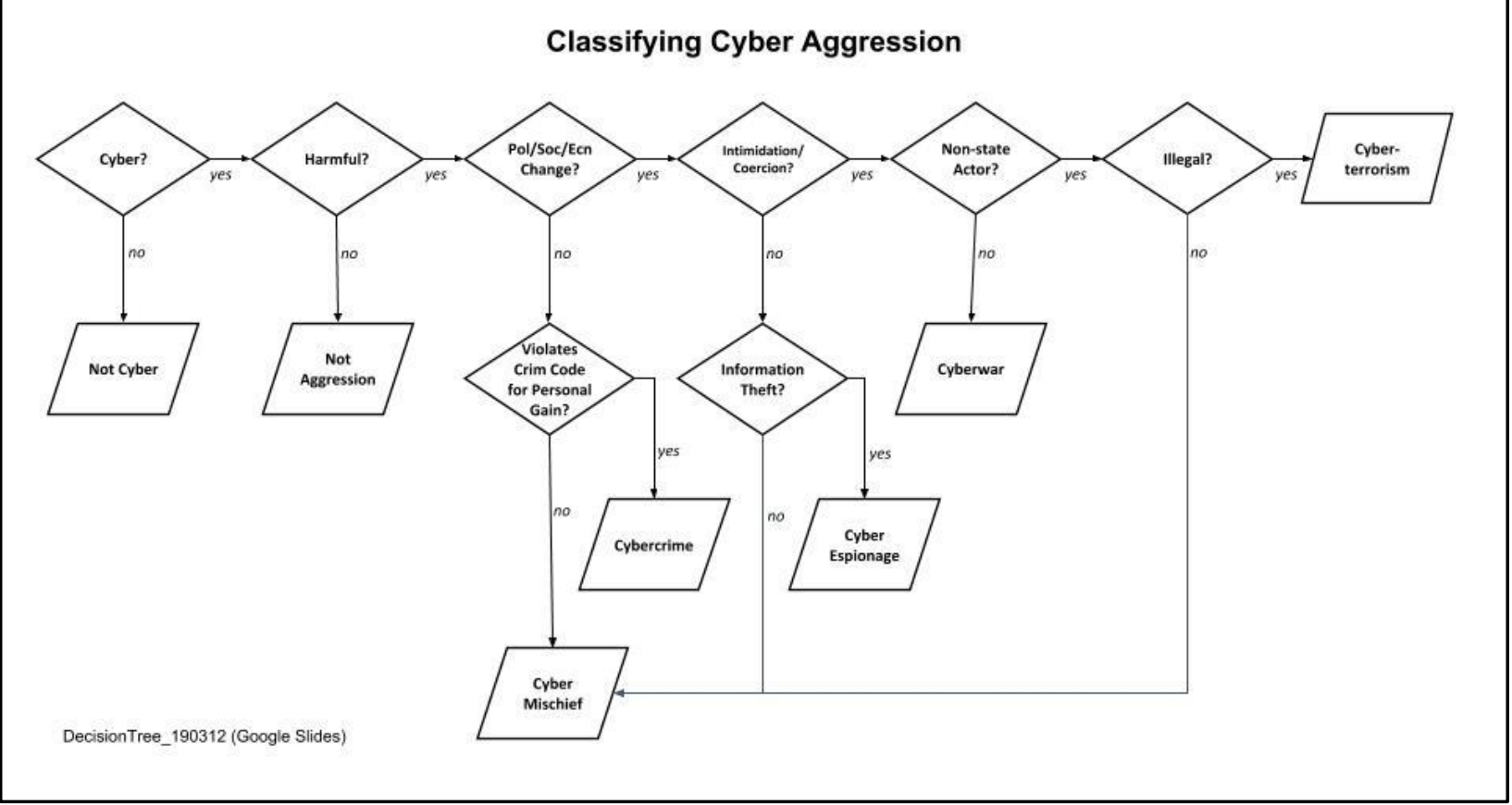

Figure 2. Decision Tree: Classifying Cyber Aggression

This definition and detailed examination of cyberterrorism are designed to help advance both terrorism- and cyberscience-related research as well as to inform policy makers of the emerging and complicated nature of cyberterrorism. The emerging role of cybertechnology in society simply complicates further the challenges terrorism researchers have in defining terrorism. This article offers some definitional clarity to terrorism researchers who may be concerned about an expansive use of "cyberterrorism" that may be inaccurately applied. It offers another dimension through which to study terrorist attacks like differentiating between bombings, assassinations, kidnappings, and other methods of attack and differentiating between civilians, military members, government officials, and other targets of attack. This paper also situates cyberterrorism within the larger phenomenon of cyber aggression and provides a process to distinguish it from other forms of cyber aggression in order to allow terrorism researchers to use the term with confidence. Establishing an accurate and robust 
definition of cyberterrorism is an important step in the development of a broader research program on cyberterrorism. Researchers can more easily investigate the causes and effects of cyberterrorism as they have an appropriate definition to work from.

As a relatively new field of inquiry, cyberscience research is still exploring its shared interests with longer standing fields of inquiry. This article offers cyberscience researchers information about vulnerabilities related to human threats to cybertechnology and, in turn, vulnerabilities related to cybertechnology threats to humans. It suggests potential research priorities by indicating the degree of harm, from merely annoying to highly disruptive and even existential, that can be inflicted through cyber means. This article offers a view of why people attack others that may help cyberscientists identify and understand what they need to defend and how they might defend it. Finally, it may familiarize cyberscience researchers with the language of salient but non-expert consumers of their studies, and help them understand the concerns of and communicate with these same consumers.

Finally, it offers policy makers a detailed view of cyberterrorism that provides leverage on a number of policy-related considerations. Among other things, it suggests the expected harm of cyberterrorism, as indicated by its low frequency of occurrence but potentially medium to high levels of damage, and gives insight into the relative urgency of cyberterrorism being actively on the political agenda. It identifies the victims of cyberterrorism, who need to be protected, and the perpetrators, who need to be thwarted. Importantly, it suggests protecting victims and thwarting perpetrators is extremely difficult due to the nature of cybertechnology, with implications for the potential regulation of cybertechnology. As well, it provides an approach to differentiating cyber-enabled behavior, which might be addressed using current 
policies for the offline world, from cyber-dependent behavior, which might benefit from policies tailored for cybertechnology.

In conclusion, given the rapid advances of cybertechnology today, it is difficult to conceptualize what cyberterrorism, or any form of cyber aggression for that matter, will look like in the years to come. One can imagine, though, a future scenario in which the expansive Internet of things -- networked interconnections between everyday devices -- exponentially multiplies aggressors' opportunities to harm others through means of cybertechnology. In fact, by some informed estimates, there may be over 21 billion devices connected to the internet by 2020 , vastly increasing the vulnerabilities of the internet to cyberattack vectors and creating what Admiral James Stavridis, former NATO Supreme Allied Commander Europe, calls a "cyberwar nightmare" (Stavridis and Weinstein 2016). This may especially be the case for efforts to create political, social, or economic change, which often relies on aggregated interests and persuasion. With the evolution and expanding reach of cybertechnology in mind, this conceptualization of cyberterrorism will hopefully serve as a fundamental mechanism through which to study, understand, and classify actors' intentions to intimidate and coerce others into political, social, and economic change. 


\section{WORKS CITED}

BBC News. 2013. “Hackers Attack Several BBC Twitter Accounts.” BBC, March 21, 2013. Accessed January 2, 2019. https://www.bbc.com/news/technology-21879230.

BBC News. 2014. “Hack Attack Causes 'Massive damage' at Steel Works." BBC, December 22, 2014. Accessed August 20, 2018. https://www.bbc.com/news/technology-30575104.

Bishop, Jonathan. 2013. "The Art of Trolling Law Enforcement: A Review and Model for Implementing 'Flame Trolling' Legislation Enacted in Great Britain (1981-2012).” International Review of Law, Computers \& Technology 27(3): 301-318.

Borghard, Erica D., and Shawn W. Lonergan. 2017. "The Logic of Coercion in Cyberspace." Security Studies 26(3): 452-481.

Brickey, Jonalan. 2012. “Defining Cyberterrorism: Capturing a Broad Range of Activities in Cyberspace." CTC Sentinel 5(8): 4-6.

Bryant, Fred B., and Bruce D. Smith. 2001. "Refining the Architecture of Aggression: A Measurement Model for the Buss-Perry Aggression Questionnaire." Journal of Research in Personality 35(2): 138-167.

Buss, Arnold H., and Mark P. Perry. 1992. "The Aggression Questionnaire." Journal of Personality and Social Psychology 63(3): 452-459.

Clarke, Richard A., and Robert K. Knake. 2010. Cyber War: The Next Threat to National Security and What to Do about It. New York: Ecco.

Clausewitz, Carl von. 1976 (1827). On War. Princeton, NJ: Princeton University Press. 
Corera, Gordon. 2016. “How France's TV5 Was Almost Destroyed by 'Russian Hackers'.” BBC News, October 10, 2016. Accessed January 2, 2019. https://www.bbc.com/news/technology-37590375.

Council of Europe. 2001. "Convention on Cybercrime." Council of Europe. Accessed August 19, 2018. https://rm.coe.int/CoERMPublicCommonSearchServices/DisplayDCTMContent?docume ntld=0900001680081561.

Council of the European Union. 2002. "Council Framework Decision on Combatting Terrorism (2002/475/JHA)." Council of the European Union. Accessed March 24, 2018. https://eurlex.europa.eu/legal-content/EN/TXT/?uri=celex:32002F0475.

Denning, Dorothy E. 2000. “Cyberterrorism.” Testimony Before the Special Oversight Panel on Terrorism, Committee on Armed Services, US House of Representatives. May 23, 2000. Accessed March 14, 2019. https://faculty.nps.edu/dedennin/publications/TestimonyCyberterrorism2000.htm.

DeWall, C. Nathan, Craig A. Anderson, and Brad J. Bushman. 2011. “The General Aggression Model: Theoretical Extensions to Violence." Psychology of Violence 1(3): 245-258.

Donnelly, Laura. 2018. "More Than 900 NHS Deaths Yearly May be Caused by IT Failings." The Telegraph, February 6, 2018. Accessed August 20, 2018. https://www.telegraph.co.uk/news/2018/02/06/900-nhs-deaths-yearly-may-causedfailings/.

Durkheim, Emile. 1895/2014. The Rules of Sociological Method: And Selected Texts on Sociology and Its Method. New York City, NY: Free Press. 
Elsom, Dan. 2017. “Attack of the Hack: Five of the Worst Cases of Cyber Crime the World Has Ever Seen." The Sun, July 31, 2017. Accessed March 24, 2018. https://www.thesun.co.uk/tech/4120942/five-of-the-worst-cases-of-cyber-crime-theworld-has-ever-seen-from-data-theft-of-one-billion-yahoo-users-to-crippling-the-nhs/.

FBI-NCCIC. 2016. “GRIZZLY STEPPE - Russian Malicious Cyber Activity.” Federal Bureau of Investigation Joint Activity Report JAR-16-20296A, December 29, 2016. Accessed November 22, 2017. https://www.us-cert.gov/sites/default/files/publications/JAR 1620296A GRIZZLY\%20STEPPE-2016-1229.pdf.

Federal Chancellery of the Republic of Austria. 2013. "Austrian Cyber Security Strategy." Accessed January 5, 2019. https://www.bmi.gv.at/504/files/130415 strategie cybersicherheit en web.pdf.

Fitzpatrick, Alex. 2013. "Pro-Syria Group Takes Credit for BBC Twitter Hack." Mashable, March 21, 2013. Accessed January 2, 2019. https://mashable.com/2013/03/21/bbc-twitterhacked/\#dhCZW4skYgqw.

Fung, Brian. 2018. “Equifax’s Massive 2017 Data Breach Keeps Getting Worse.” Washington Post, March 1, 2018. Accessed March 24, 2018. https://www.washingtonpost.com/news/the-switch/wp/2018/03/01/equifax-keepsfinding-millions-more-people-who-were-affected-by-its-massive-data-breach.

Gartzke, Erik. 2013. "The Myth of Cyberwar: Bringing War in Cyberspace Back Down to Earth.” International Security 38(2): 41-73. 
Giles, Keir, and William Hagestad. 2013. “Divided by a Common Language: Cyber Definitions in Chinese, Russian and English." In 2013 5th International Conference on Cyber Conflict (CYCON 2013) IEEE, pp. 1-17.

Gordon, Sara, and Richard Ford. 2002. “Cyberterrorism?” Computers \& Security 21(7): 636-647.

Grant, Rebecca. 2017. “The Disturbing Rise of Cyberattacks Against Abortion Clinics.” Wired, October 5, 2017. Accessed March 24, 2018. https://www.wired.com/story/cyberattacksagainst-abortion-clinics/.

Grotius, Hugo. 2012 (1625). The Law of War and Peace. Cambridge, UK: Cambridge University Press.

Jarvis, Lee, Stuart Macdonald, and Lella Nouri. 2014. "The Cyberterrorism Threat: Findings from a Survey of Researchers." Studies in Conflict \& Terrorism 37(1): 68-90.

Johnson, A. 1935. Warfare Encyclopedia of the Social Sciences, vol. 15. New York, NY: Macmillan.

Joint Chiefs of Staff. 2014. "Counterterrorism." Joint Chiefs of Staff Joint Publication 3-26. Washington, DC: US Department of Defense. Joint Chiefs of Staff. 2018. “Cyberspace Operations, Joint Publication 3-12." US Department of Defense. Accessed June 29, 2018. http://www.jcs.mil/Portals/36/Documents/Doctrine/pubs/jp3 12.pdf. Joint Staff Director of Operations. 2013. “Cyberspace Operations, Joint Publication 3-12(R)." Joint Chiefs of Staff, US Department of Defense. Washington, DC: US Department of Defense. 
Kubic, Thomas T. 2001. Testimony Before the Committee on the Judiciary, Subcommittee on Crime, US House of Representatives. June 12, 2001. Accessed March 14, 2019. https://archives.fbi.gov/archives/news/testimony/the-fbis-perspective-on-thecybercrime-problem.

Kuehl, Daniel T. 2009. "From Cyberspace to Cyberpower: Defining the Problem," in Franklin D. Kramer, Stuart Starr, and Larry K. Wentz, eds., Cyberpower and National Security. Washington, D.C.: National Defense University.

Langner, Ralph. 2013. "Stuxnet's Secret Twin: The Real Program to Sabotage Iran's Nuclear Facilities Was Far More Sophisticated Than Anyone Realized." Foreign Policy, November 19, 2013. Accessed November 22, 2017. http://foreignpolicy.com/2013/11/19/stuxnetssecret-twin/.

Lewis, James Andrew. 2010. "The Cyber War Has Not Begun." Center for Strategic and International Studies. Accessed March 14, 2019. https://csisprod.s3.amazonaws.com/s3fspublic/legacy files/files/publication/100311_TheCyberWarHasNotBegun.pdf. Lynn, William J. 2010. “Defending a New Domain: The Pentagon's Cyberstrategy." Foreign Affairs 89(5): 97-108.

Maras, Marie-Helen. 2017 Cybercriminology. Oxford, UK: Oxford University Press. Maurer, Tim. 2018. Cyber Mercenaries: The State, Hackers, and Power. Cambridge, UK: Cambridge University Press.

McCarthy, Nick. 2013. “Police Officer Will Not Face Charges Over Alleged Online Abuse.” BirminghamLive, July 31, 2013. Accessed December 18, 2018. 
https://www.birminghammail.co.uk/news/local-news/stechford-based-police-officer$\underline{\text { not-face-5387481. }}$

Melendez, Steven. 2017. “Online Sleuths Are Outing Racists, But Should They?" Fast Company, August 19, 2017. Accessed December 18, 2018.

https://www.fastcompany.com/40456128/ethics-of-online-sleuths-outing-racists-aftercharlottesville.

Nakashima, Ellen, and Karen DeYoung. 2018. "Trump Administration Hits Iranian Hacker Network with Sanctions, Indictments in Vast Global Campaign." Washington Post, March 23, 2018. Accessed March 24, 2018. https://www.washingtonpost.com/world/nationalsecurity/trump-administration-hits-iranian-hacker-network-with-sanctions-indictmentsin-vast-global-campaign/2018/03/23/4481721c-2e16-11e8-8688e053ba58f1e4 story.html.

New Zealand Department of the Prime Minister and Cabinet. 2015. "National Plan to Address Cybercrime." Accessed August 18, 2018. https://www.dpmc.govt.nz/sites/default/files/2017-03/nz-cyber-security-cybercrimeplan-december-2015.pdf.

Parti, Katalin, Tibor Kiss, and Gergely Koplányi. 2018. “Architecture of Aggression in Cyberspace: Testing Cyber Aggression in Young Adults in Hungary." International Journal of Cybersecurity Intelligence \& Cybercrime 1(1): 56-68.

Perlroth, Nicole, Mark Scott, and Sheera Frenkel. 2017. “Cyberattack Hits Ukraine Then Spreads Internationally." New York Times, June 27, 2017. Accessed August 18, 2018. https://www.nytimes.com/2017/06/27/technology/ransomware-hackers.html. 
Ministry of Information and Communications Technology. 2014. "Qatar National Cyber Security Strategy." Accessed August 18, 2018. http://www.motc.gov.qa/sites/default/files/national_cyber_security_strategy.pdf.

RAND. n.d. “Cyber Warfare.” RAND Corporation. Accessed August 18, 2018. https://www.rand.org/topics/cyber-warfare.html.

Rid, Thomas. 2012. "Cyber War Will Not Take Place." The Journal of Strategic Studies 35(1): 532.

Rosenzweig, Paul. 2013. Cyber Warfare: How Conflicts in Cyberspace are Challenging America and Changing the World. Santa Barbara, CA: Praeger.

Rutenberg, Jim. 2017. “RT, Sputnik and Russia's New Theory of War.” New York Times Magazine, September 13, 2017. Accessed December 18, 2018. https://www.nytimes.com/2017/09/13/magazine/rt-sputnik-and-russias-new-theory-ofwar.html.

Sanger, David. 2018. The Perfect Weapon. New York: Crown.

Sayfayn, Nabil, and Stuart Madnick. 2017. “Cybersafety Analysis of the Maroochy Shire Sewage Spill, Working Paper CISL\# 2017-09." Cybersecurity Interdisciplinary Systems Laboratory (CISL), Sloan School of Management, Massachusetts Institute of Technology, May 2017. Accessed March 23, 2019. http://web.mit.edu/smadnick/www/wp/2017-09.pdf.

Schmid, Alex P. 2011. "The Definition of Terrorism." In The Routledge Handbook of Terrorism Research, edited by A.P. Schmid, pp. 39-99. London: Routledge. Schmitt, Michael N. 2013. Tallinn Manual on the International Law on Cyber Warfare. Cambridge, UK: Cambridge University Press. 
Secretariat of the Security and Defence Committee (Finland). 2013. "Finland's Cyber Security Strategy." Accessed January 5, 2019. https://www.enisa.europa.eu/topics/nationalcyber-security-strategies/ncss-map/FinlandsCyberSecurityStrategy.pdf.

Shively, Nick. 2015. “Cyber Attack Leaks Planned Parenthood Employee Information.” Los Angeles Times, July 28, 2015. Accessed March 24, 2018. https://www.latimes.com/business/la-fi-planned-parenthood-hacked-20150727story.html.

Siegel, Alexandra A., and Joshua A. Tucker. 2018. "The Islamic State’s Information Warfare: Measuring the Success of ISIS's Online Strategy." Journal of Language and Politics 17(2): 258-280.

Singer, J. David, and Melvin Small. 1972. The Wages of War, 1816-1965: A Statistical Handbook. New York: Wiley.

Singer, P. W., and Emerson T. Brooking. 2018. LikeWar: The Weaponization of Social Media. New York: Houghton Mifflin Harcourt.

Smith, Bryan, William Yurcik, and David Doss. 2002. “Ethical Hacking: The Security Justification Redux." In 2002 International Symposium on Technology and Society (ISTAS'02) IEEE-Social Implications of Information and Communication Technology, Proceedings (Cat. No.02CH37293), pp. 374-379.

Smith, Peter K. 2012. "Cyberbullying and Cyber Aggression." In Handbook of School Violence and School Safety, 2nd edition, edited by Shane R. Jimerson, Amanda B. Nickerson, Matthew J. Mayer, and Michael J. Furlong, pp. 93-104. New York, NY: Routledge. 
START. 2017. Global Terrorism Database: Codebook: Inclusion Criteria and Variables (July 2018). College Park, MD: University of Maryland.

Stavridis, James, and Dave Weinstein. 2016. "The Internet of Things is a Cyberwar Nightmare." Foreign Policy, November 3, 2016. Accessed February 12, 2019. https://foreignpolicy.com/2016/11/03/the-internet-of-things-is-a-cyber-warnightmare/.

Stoll, Clifford. 1988. "Stalking the Wily Hacker." Communications of the ACM 31(5): 484-497. Tafoya, William L. 2011. "Cyber Terror.” US Department of Justice, FBI Law Enforcement Bulletin, November 1, 2011. Accessed December 18, 2018. https://leb.fbi.gov/articles/featured-articles/cyber-terror.

Taleb, Nassim. 2008. The Black Swan: The Impact of the Highly Improbable. New York, NY: Penguin.

Tamkin, Emily. 2017. "10 Years After the Landmark Attack on Estonia, Is the World Better Prepared for Cyber Threats?" Foreign Policy, April 27, 2017. Accessed August 19, 2018. https://foreignpolicy.com/2017/04/27/10-years-after-the-landmark-attack-on-estoniais-the-world-better-prepared-for-cyber-threats/.

Thacker, Scott, and Mark D. Griffiths. 2012. “An Exploratory Study of Trolling in Online Video Gaming." International Journal of Cyber Behavior, Psychology and Learning 2(4): 17-33.

Thomas, Douglas, and Brian Loader. 2000. Cybercrime: Law Enforcement, Security and Surveillance in the Information Age. London, UK: Routledge.

Toppa, Sabrina. 2017. “Abuse in Pakistan: 'I'm More Scared of Harassment Online Than Offline.'" The Guardian, August 9, 2017. Accessed December 18, 2018. 
https://www.theguardian.com/global-development-professionals-

network/2017/aug/09/abuse-in-pakistan-im-more-scared-of-harassment-online-than-

offline.

Uma, M., and Ganapathi Padmavathi. 2013. "A Survey on Various Cyber Attacks and their Classification." IJ Network Security 15(5): 390-396.

United Nations. 2017. "Statement Attributable to the Spokesman for the Secretary-General on the United Nations Office for Counter-Terrorism." United Nations. Accessed March 24, 2018. https://www.un.org/sg/en/content/sg/statement/2017-06-15/statementattributable-spokesman-secretary-general-united-nations. United Nations Office on Drugs and Crime. n.d. "Global Programme on Cybercrime." United Nations. Accessed August 18, 2018.

https://www.unodc.org/unodc/en/cybercrime/global-programme-cybercrime.html.

United Nations Security Council Resolution 1566. 2004. "Threats to International Peace and Security by Terrorist Acts." United Nations. Accessed March 24, 2018. https://www.un.org/ruleoflaw/blog/document/security-council-resolution-1566-2004on-threats-to-international-peace-and-security-caused-by-terrorist-acts/.

US Department of Justice. 2014. "U.S. Charges Five Chinese Military Hackers for Cyber Espionage Against U.S. Corporations and a Labor Organization for Commercial Advantage." US Department of Justice, May 19, 2014. Accessed February 28, 2018. https://www.justice.gov/opa/pr/us-charges-five-chinese-military-hackers-cyberespionage-against-us-corporations-and-labor. 
US Department of Justice. 2015. “Computer Analyst Sentenced to Three Years in Prison for Stealing Trade Secrets from Citadel and Previous Employer." US Department of Justice, January 15, 2015. Accessed February 28, 2018. https://www.justice.gov/usaondil/pr/computer-analyst-sentenced-three-years-prison-stealing-trade-secrets-citadeland.

US Department of Justice. 2016. “ISIS Linked Hacker Sentenced to 20 Years in Prison, Release 16-1085." US Department of Justice, September 23, 2016. Accessed March 9, 2018. https://www.justice.gov/usao-edva/pr/isil-linked-hacker-sentenced-20-years-prison.

US Defense Security Service. n.d. "Cyber Threats.” US Defense Security Service, Counterintelligence Directorate. Accessed November 17, 2017. http://www.dss.mil/documents/ci/CyberThreats.pdf.

Valeriano, Brandon, and Ryan C. Maness. 2015. Cyber War Versus Cyber Realities: Cyber Conflict in the International System. Oxford, UK: Oxford University Press.

Warner, Michael. 2012. "Cybersecurity: A Pre-history." Intelligence and National Security 27(5): 781-799.

We Are Social. 2018. “Global Digital Report 2018.” Accessed March 14, 2019. https://digitalreport.wearesocial.com/.

Weissbrodt, David. 2013. “Cyber-Conflict, Cyber-Crime, and Cyber-Espionage." Minnesota Journal of International Law 22(2): 347-387.

Wray, Christopher. 2018. “Digital Transformation: Using Innovation to Combat the Cyber Threat." Remarks prepared for delivery to the Boston College/FBI - Boston Conference on Cyber Security in Boston, Massachusetts, March 7, 2018. Accessed March 14, 2019. 
https://www.fbi.gov/news/speeches/digital-transformation-using-innovation-tocombat-the-cyber-threat.

Wright, Quincy. 1942. A Study of War. Chicago: University of Chicago Press.

Yar, Majid. 2013. Cybercrime and Society. $2^{\text {nd }}$ edition. Los Angeles, CA: Sage Publications. Zakem, Vera, Megan K. McBride, and Kate Hammerberg. 2018. “Exploring the Utility of Memes for U.S. Government Influence Campaigns." Center for Naval Analysis, April 2018. Accessed March 15, 2019. https://www.cna.org/CNA files/PDF/DRM-2018-U$\underline{\text { 017433-Final.pdf }}$

Zhou, Zunyou. 2015. "How China Defines Terrorism." The Diplomat, February 13, 2015. Accessed March 24, 2018. https://thediplomat.com/2015/02/how-china-definesterrorism/. 